\title{
Molecular, biochemical and kinetic analysis of a novel, thermostable lipase (LipSm) from Stenotrophomonas maltophilia Psi-1, the first member of a new bacterial lipase family (XVIII)
}

Maria Parapouli ${ }^{1}$, Athanasios Foukis ${ }^{1}$, Panagiota-Yiolanda Stergiou ${ }^{1}$, Maria Koukouritaki ${ }^{1}$, Panagiotis Magklaras ${ }^{1}$, Olga A. Gkini' ${ }^{1}$ Emmanuel M. Papamichael ${ }^{1}$, Amalia-Sofia Afendra ${ }^{1}$ and Efstathios Hatziloukas ${ }^{1,2^{*}}$

\begin{abstract}
Background: Microbial lipases catalyze a broad spectrum of reactions and are enzymes of considerable biotechnological interest. The focus of this study was the isolation of new lipase genes, intending to discover novel lipases whose products bear interesting biochemical and structural features and may have a potential to act as valuable biocatalysts in industrial applications.

Results: A novel lipase gene (lipSm), from a new environmental Stenotrophomonas maltophilia strain, Psi-1, originating from a sludge sample from Psittaleia (Greece), was cloned and sequenced. lipSm was further overexpressed in E. coli BL21(DE3) and the overproduced enzyme LipSm was purified and analyzed in respect to its biochemical and kinetic properties. In silico analysis of LipSm revealed that it is taxonomically related to several uncharacterized lipases from different genera, which constitute a unique clade, markedly different from all other previously described bacterial lipase families. All members of this clade displayed identical, conserved consensus sequence motifs, i.e. the catalytic triad $(S, D, H)$, and an unusual, amongst bacterial lipases, Y-type oxyanion hole. 3D-modeling revealed the presence of a lid domain structure, which allows LipSm to act on small ester substrates without interfacial activation. In addition, the high percentage of alanine residues along with the occurrence of the AXXXA motif nine times in LipSm suggest that it is a thermostable lipase, a feature verified experimentally, since LipSm was still active after heating at $70^{\circ} \mathrm{C}$ for $30 \mathrm{~min}$.
\end{abstract}

Conclusions: The phylogenetic analysis of LipSm suggests the establishment of a new bacterial lipase family (XVIII) with LipSm being its first characterized member. Furthermore, LipSm is alkaliphilic, thermostable and lacks the requirement for interfacial activation, when small substrates are used. These properties make LipSm a potential advantageous biocatalyst in industry and biotechnology.

Keywords: Thermostable bacterial lipase, Stenotrophomonas maltophilia, Lipase gene cloning and overexpression, Enzyme purification, Enzyme kinetics, Bacterial lipase families

\footnotetext{
*Correspondence: ehatzilu@cc.uoi.gr

2 Department of Biological Applications \& Technologies, University

of loannina, University Campus, 45110 loannina, Greece

Full list of author information is available at the end of the article
} 


\section{Background}

Lipases (triacylglycerol acylhydrolase, E.C. 3.1.1.3) are enzymes, which hydrolyze triacylglycerols and release diand/or monoglycerides, fatty acids and glycerol [1]. However, in low water content systems, they can also catalyze the reverse reactions i.e. esterifications or transesterifications $[2,3]$. Due to these unique properties, lipases are enzymes of considerable biotechnological interest and find use in a broad spectrum of applications [4] including, among others, food technology, bioremediation, chemical industry and medical sciences $[2,5,6]$.

Lipases are produced by both higher eukaryotes (plants and animals) and various microorganisms including fungi and bacteria [7]. Microbial lipases are reported to be advantageous when compared to enzymes of animal or plant origin, since they have a low cost-high production capacity, ease for genetic manipulation and are more stable in terms of activity [8]. These facts have led to an increased interest in the isolation of novel microbial lipases, especially for those, bearing biotechnological properties, which can be exploited in various industrial applications.

All lipases conform to $\alpha / \beta$ hydrolase fold [9] and at most share common structural and functional elements such as: (i) the catalytic triad ( $\mathrm{S}, \mathrm{H}$ and $\mathrm{D})$, (ii) the conserved pentapeptide GXSXG in which the catalytic $S$ is embedded, (iii) the mobile "lid" which shields the catalytic site, and (iv) the interfacial activation mechanism which regulates lid opening enabling the access of the substrates to the catalytic site $[10,11]$ and triggers the development of the so-called oxyanion hole [12]. However, despite their common features, lipases exhibit an extensive sequence variation. In the Lipase Engineering Database (LED) [12] lipases are assigned in three classes named GGGX, GX and $Y$ according to the sequence and structure of the oxyanion hole [13].

However, when sequence identity and biochemical properties are considered, the diversity of these enzymes is much greater. Arpigny and Jaeger, classified first lipolytic enzymes in eight families (I-VIII) [14]. Since then, nine new families (IX-XVII) were further established [15-17]. Currently there are only two reports concerning the same S. maltophilia lipase gene (NCBI Accession No. KC014616), encoding LipSM54, a 60 kDa enzyme with particular features that established lipolytic family XVI $[15,18]$.

In this study, we present: (a) the cloning and overexpression of a novel lipSm gene from a new S. maltophilia strain, Psi-1, isolated from a sludge sample from a waste treatment facility at Psittaleia, Greece, (b) the biochemical and kinetic analysis of the purified lipase LipSm and (c) in silico analysis of the phylogenetic relationship of the encoded LipSm to other lipases, as well as its structural features, which provide evidence that $\mathrm{LipSm}$ is the first characterized member of a novel lipase family, indexed XVIII. To our knowledge, this is the first report on the production of an S. maltophilia lipase with such unusual structural and biochemical features.

\section{Results}

Selection and identification of the lipase producing strain Psi-1

Initial isolation on LA plates revealed the presence of 14 different morphological phenotypes in sludge samples collected from the waste treatment facilities of Volos and Psittaleia (Greece). Amongst them, only 5 phenotypes were found positive for lipase activity, using the true lipases' specific Rhodamine B-olive oil agar plates assay, according to Kouker and Jaeger [19]. At least three isolates from each phenotype were preliminarily characterized using Intergenic Spacer (IGS) based molecular taxonomy. BLAST search revealed the presence of only one non-pathogenic species, belonging to S. maltophilia (data not shown). To verify the IGS-based taxonomic results, a strain designated Psi-1 (strain deposition number: LMG: 29922), randomly selected among the others, was further processed and its $16 \mathrm{~S}$ rRNA gene was amplified, cloned in vector pBlueScript II KS (+) and sequenced. According to BLAST search results, Psi-1 was assigned to $S$. maltophilia species exhibiting a sequence homology of > 99\% (GenBank Accession No. KX380193). The phylogenetic position of Psi-1 was traced in the phylogenetic tree derived from the 16S rRNA gene sequences of closely related taxa by a neighbor joining algorithm in MEGA software (Fig. 1).

\section{Amplification, cloning and sequencing of a putative secreted lipase gene (lipSm)}

According to the bioinformatic analyses of the whole genome sequences of $S$. maltophilia strains deposited in the data banks, primers SMLF and SMLR were designed, to amplify a large DNA fragment (1850 bp) containing a putative secreted lipase gene, which was further cloned and sequenced. Based on these data, specific primers SMLPETF and SMLPETR were designed, in order to amplify and clone the putative lipSm ORF. Sequencing results verified the presence of the lipase gene (lipSm; 1203 bp; GenBank Accession No. KX353755) exhibiting its closest homology (91.8\%) with the corresponding lipase gene from S. maltophilia strain K279a [20].

\section{Bioinformatic analysis of the deduced amino acid sequence of LipSm}

Analysis of the deduced amino acid sequence of LipSm (400 residues) revealed a predicted molecular mass (MM) of $42.08 \mathrm{kDa}$ and a $\mathrm{pI}$ of 7.23. Pfam analysis classified 


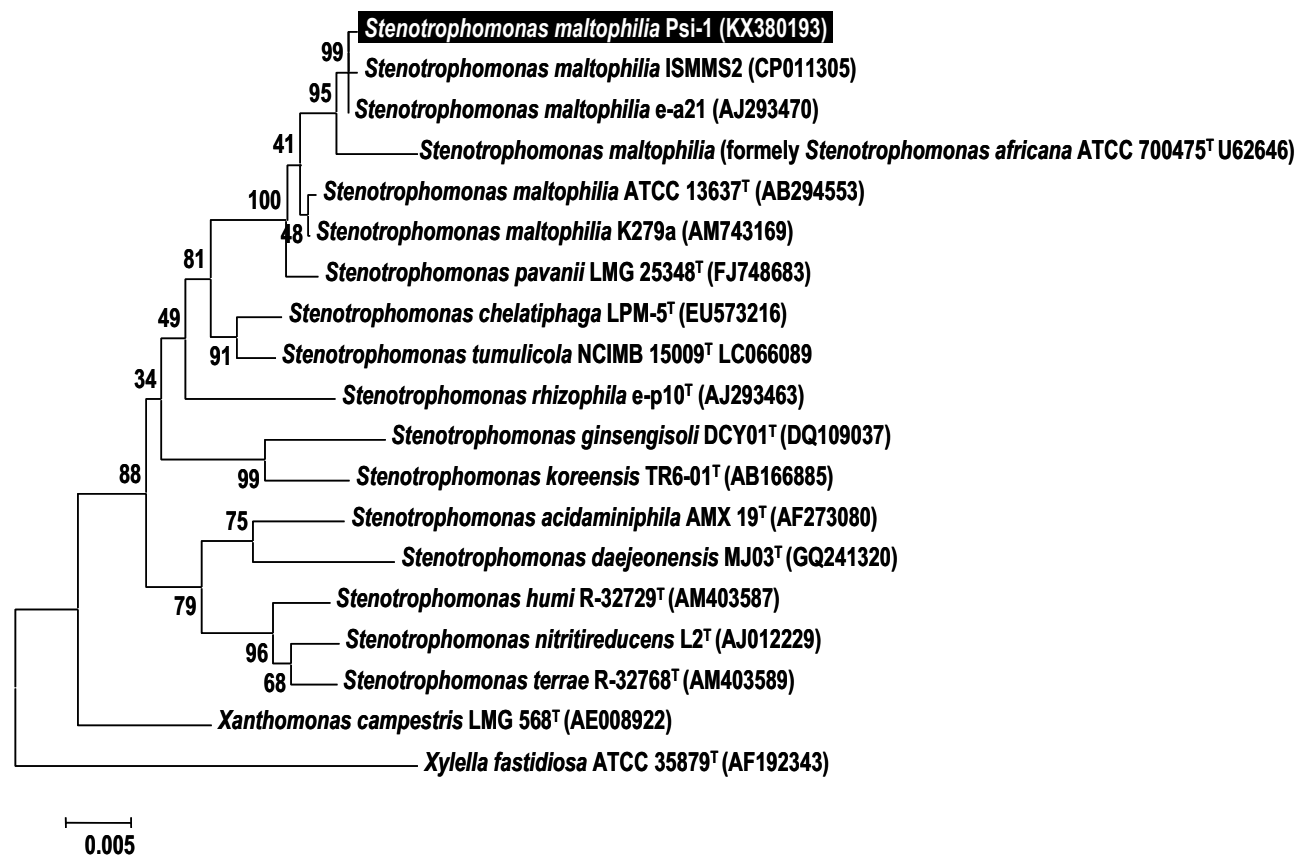

Fig. 1 Phylogenetic position of S. maltophilia Psi-1 amongst other strains of S. maltophilia and related species. Phylogenetic analyses were conducted with algorithm MEGA. The tree was constructed with a neighbour joining algorithm using $16 \mathrm{~S}$ rRNA gene sequences. Xylella fastidiosa served as an outgroup. The percentage of replicate trees in which the associated taxa clustered together in the bootstrap test (1000 replicates) are shown next to the branches. The scale bar indicates the number of substitutions per nucleotide position

LipSm as a secretory lipase, showing maximum identity at its C-terminus (amino acids 119-284). The presence of a signal peptide with a cleavage site located between residues 29 and 30 (LAA-AP) lends further support to the prediction of the extracellular location of the lipase, with the mature form (371 amino acid residues) exhibiting a calculated MM of $39.09 \mathrm{kDa}$ and a pI value of 6.52 . Sequence analysis of mature LipSm revealed the presence of the characteristic nucleophilic elbow (pentapeptide GHSQG), which includes the catalytic serine residue $\left(\mathrm{S}^{154}\right)$. Furthermore, mature LipSm was found to contain a high percentage of alanine residues (16.7\%) along with a 9-times presence of the motif AXXXA, which both have been reported as significant features of thermostable lipases [21]. BLAST searches revealed several nonredundant, putative, uncharacterized protein sequences showing high similarity to LipSm. Specifically, LipSm was found to share an up to $99 \%$ sequence identity with lipases from other strains of S. maltophilia. It also shares 93 and 91\% identities with lipases from Pseudomonas geniculata and P. aeruginosa, respectively, as well as 86 and $87 \%$ identities with two lipases from Stenotrophomonas pavanii. Sequence identity of the novel LipSm with several actinobacterial lipases from Gordonia sp. and Rhodococcus sp. did not exceed 48\%. For phylogenetic analysis, 38 lipolytic enzymes were selected as characteristic members of all existing bacterial lipase families along with 16 other proteins displaying identity with LipSm ranging from 45 to 99\%. As depicted in Fig. 2, LipSm clusters together with the proteobacterial lipases from other S. maltophilia strains and the lipases from $P$. geniculata and $P$. aeruginosa. Under the same root are also found the S. pavanii lipases, however at a greater phylogenetic distance from LipSm, whereas the actinobacterial lipases constitute their own distinct, clearly distinguishable group. Figure 2 shows further that all other lipolytic families constitute different clades of the phylogenetic tree. Furthermore, BLAST search within LED [12] revealed a limited homology with lipases belonging to Candida antarctica lipase A like superfamily (abH38).

The 3D homology model constructed using the CALA (Protein Data Bank ID 2VEO) as a template, revealed a common $\alpha / \beta$ hydrolase fold. Despite the limited overall sequence identity of LipSm and CALA (ca. $23 \%$ as calculated by Clustal 2.1), the alignment (alignment score 0.050; RMSD $1.123 \AA$ ) of these two enzymes reveals a remarkable, structural similarity, which includes the catalytic triad (2VEO: $\mathrm{S}^{184}, \mathrm{D}^{334}, \mathrm{H}^{366}$; LipSm: $\mathrm{S}^{154}, \mathrm{D}^{299}, \mathrm{H}^{330}$ ) and the lid domain (2VEO: $\mathrm{S}^{217}$ up to $\mathrm{E}^{308}$; LipSm: $\mathrm{A}^{188}$ up to $\mathrm{Y}^{279}$ ), as depicted in Fig. 3a. Moreover, a consensus motif containing the conserved glutamine $\left(Q^{155}\right)$ and tyrosine $\left(\mathrm{Y}^{211}\right)$ are located near the catalytic serine $\left(\mathrm{S}^{154}\right)$, 


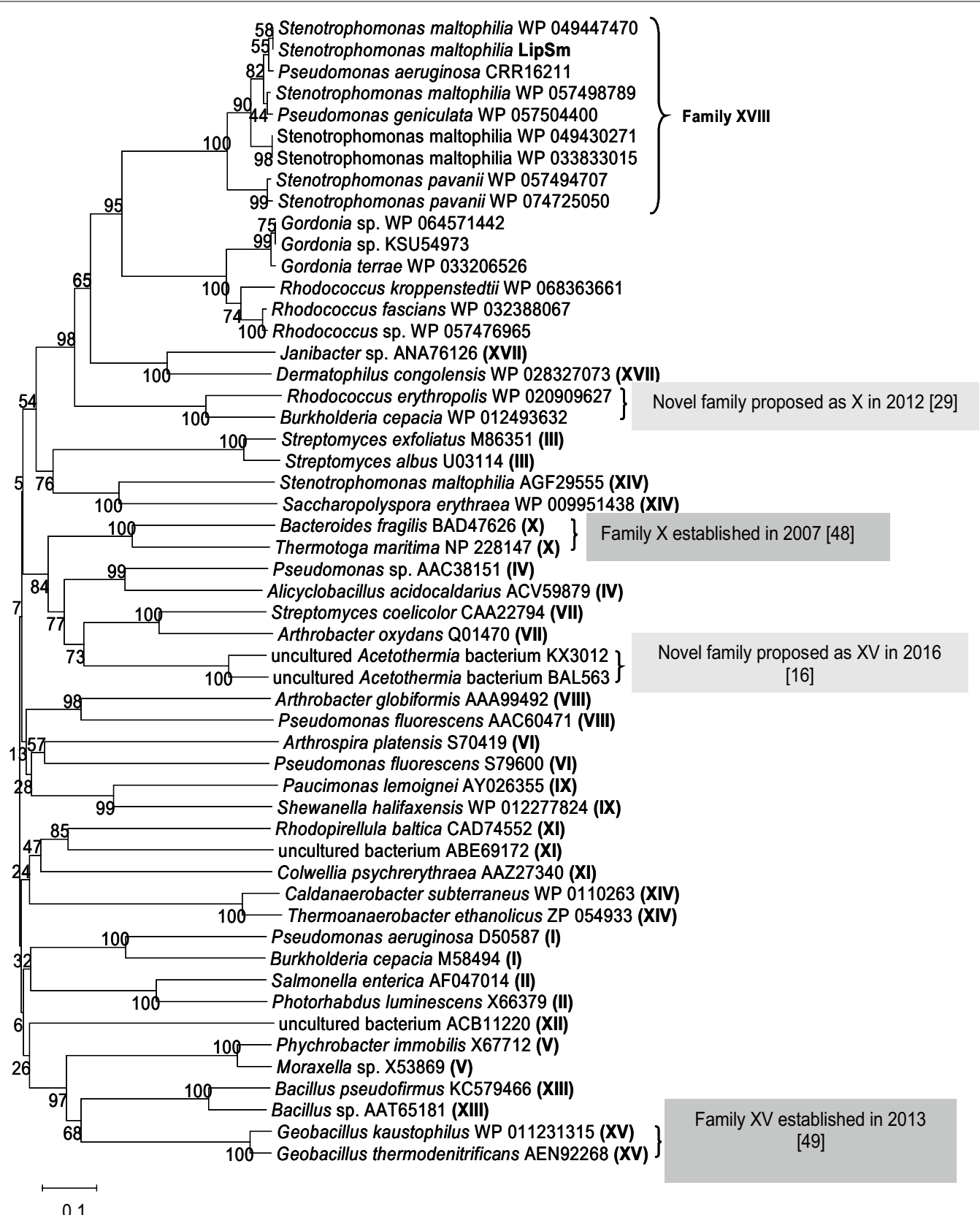

Fig. 2 Phylogenetic dendrogram indicating the position of LipSm as the first characterized member of the novel family XVIII. Latin numbers in parentheses indicate family indexes. Phylogenetic analyses were conducted with algorithm MEGA. The evolutionary history was inferred using the Neighbor-Joining method. The percentage of replicate trees in which the associated taxa clustered together in the bootstrap test (1000 replicates) are shown next to the branches. Scale bar indicates substitutions per site

composing an unusual, among bacterial lipases, Y-type oxyanion hole, as it was shown during the docking studies (Fig. 3b). Apart from the extended sequence identity of LipSm with members of its clade (Fig. 2), a multiple alignment among them revealed a high degree of conservation of important structural/functional features such as the catalytic triad, and the oxyanion hole (Fig. 4; Additional file 1).

\section{Cloning, overexpression and purification of lipSm}

Putative lipSm ORF was amplified accordingly to contain the restriction sites for $\mathrm{NdeI}$ (at its $5^{\prime}$-end) and $\mathrm{XhoI}$, 


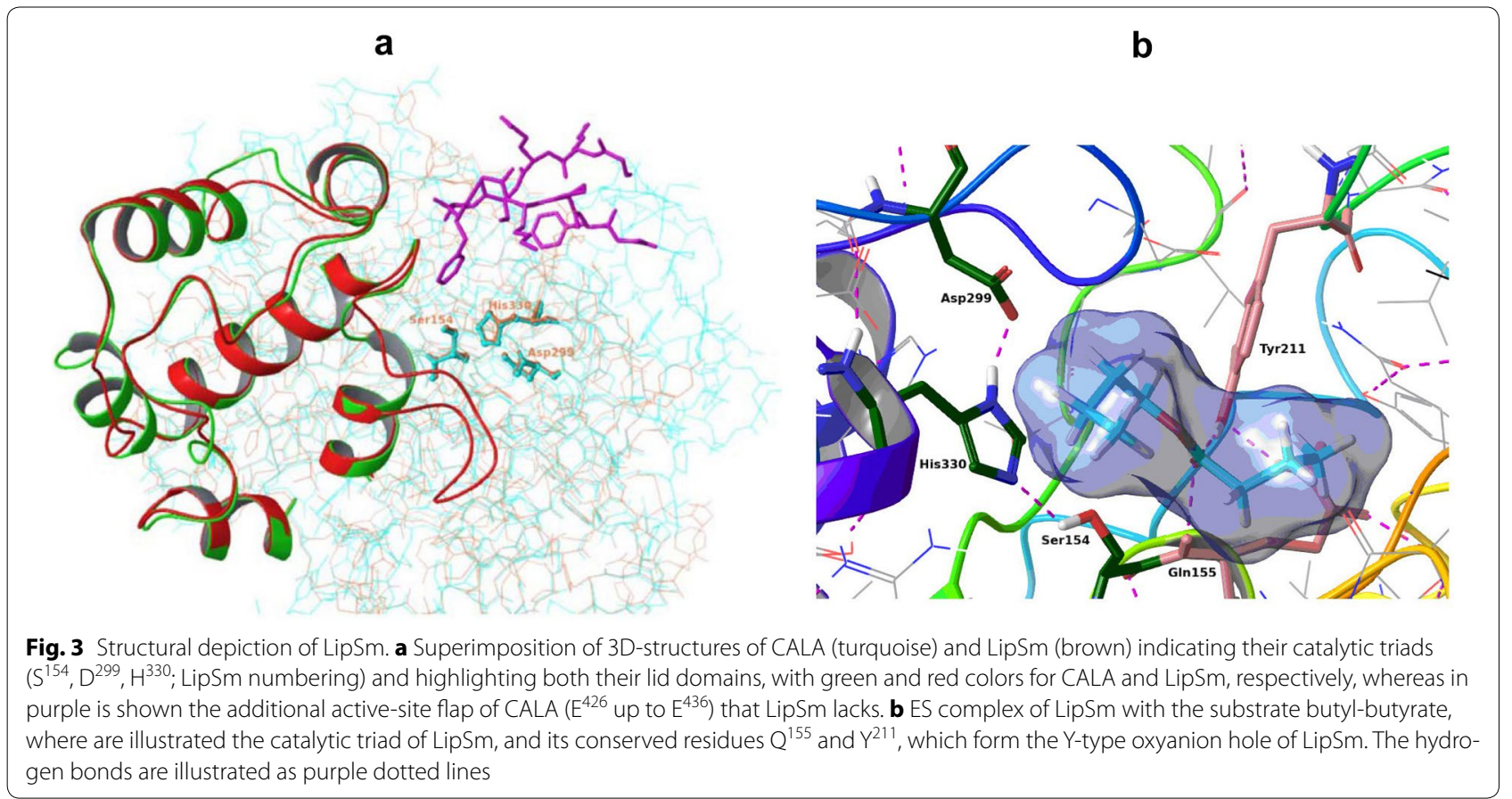

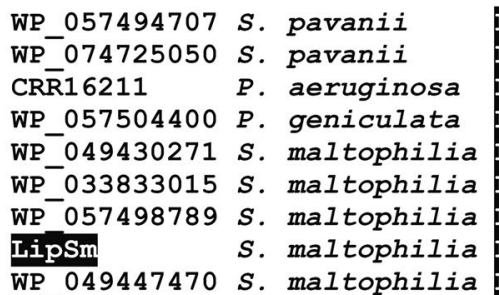

WP 049447470 s. maltophilia

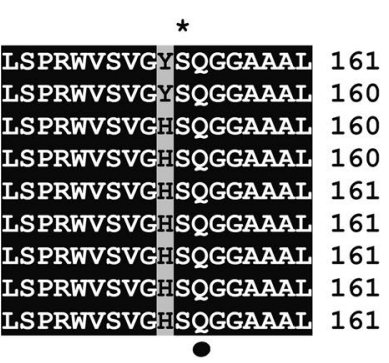
WP_057494707 S. pavanii WP_074725050 S. pavanii CRR̄16211 P. aeruginosa WP_057504400 P. geniculata WP 049430271 S. maltophilia WP_033833015 S. maltophilia WP 057498789 S. maltophilia LipSm S. maltophilia WP_049447470 s. maltophilia

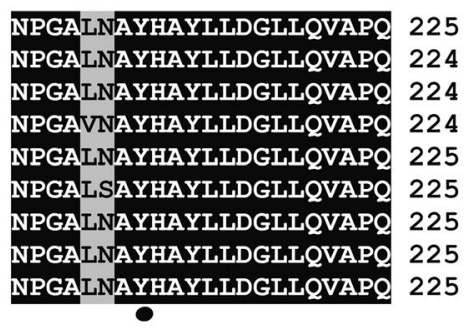

*

\begin{abstract}
WP_057494707 S. pavanii WP 074725050 S. pavanii CRR̄16211 P. aeruginosa WP 057504400 P. geniculata WP 049430271 S. maltophilia WP $033833015 \mathrm{~S}$. maltophilia WP 057498789 S. maltophilia IipSm S. maltophilia WP_049447470 s. maltophilia
\end{abstract}

Fig. 4 Blocks of conserved sequences amongst LipSm and other members of novel family XVIII. Identical and equivalent amino acids are on black or grey background, respectively. Stars and dots indicate amino acid residues constituting the catalytic triad and oxyanion hole, respectively 
and subsequently cloned and overexpressed in an E. coli BL21(DE3)/pET29c(+) system. Interestingly, two bands appeared to be overexpressed on SDS polyacrylamide gels (Fig. 5a, indicated by arrows) corresponding to the $\mathrm{MM}$ of the premature enzyme form $(44 \mathrm{kDa})$, as well as its mature form $(40.7 \mathrm{kDa})$ generated after the removal of the signal peptide in E. coli BL21(DE3) cells (Fig. 5a). These molecular masses are in perfect agreement with the predicted ones of the premature LipSm enzyme and its mature form (42.08 and $39.09 \mathrm{kDa}$, respectively), when taken into account the additional 8 amino acid residues, originating from the inserted $\mathrm{XhoI}$ site and the C-terminus $6 \times$ histidine-tag region. Mature LipSm was further purified from the total-soluble protein fraction of the recombinant $E$. coli $\mathrm{BL} 21(\mathrm{DE} 3) / \mathrm{pET} 29 \mathrm{c}:$ :lipSm clone as described in "Methods" section (Fig. 5b).

\section{Biochemical and kinetic analysis of LipSm}

The novel lipase LipSm hydrolyzes the substrates Ac4-NPh, Bu-4-NPh and $\mathrm{La}-4-\mathrm{NPh}$, exhibiting Michaelis-Menten kinetics in buffers lacking $\mathrm{EDTAK}_{2}$, while its activity was unaffected in the presence of DTT. However, the limited solubility of the two latter substrates in the used reaction buffer may have influenced the estimates of the corresponding Michaelis-Menten parameters (Table 1).

The Michaelis-Menten parameters of the novel lipase LipSm were evidently affected in the presence of higher concentrations of the salts $\mathrm{CaCl}_{2}, \mathrm{MgCl}_{2}, \mathrm{MnCl}_{2}$, and $\mathrm{NaCl}$ (hydrolysis of substrate Ac-4-NPh). In the case of $[\mathrm{NaCl}]=10 \mathrm{mM}$, the values of both $k_{\text {cat }} / K_{\mathrm{m}}$ and $k_{\text {cat }}$ were decreased at about $50 \%$, whereas the value of $K_{\mathrm{m}}$ remained unaffected; this is not uncommon. A negative
Table 1 Estimation of Michaelis-Menten parameters for the three substrates used in this study

\begin{tabular}{lcll}
\hline Substrates & $\boldsymbol{k}_{\mathbf{c a t}} / \boldsymbol{K}_{\mathbf{m}}\left(\mathbf{M}^{-\mathbf{1}} \mathbf{s}^{\mathbf{- 1}}\right)$ & $\boldsymbol{k}_{\mathbf{c a t}}\left(\mathbf{s}^{\mathbf{- 1}}\right)$ & $\boldsymbol{K}_{\mathbf{m}}(\mathbf{m M})$ \\
\hline 4-Nitrophenyl acetate & 3.671 & $1.736 \times 10^{-3}$ & 0.473 \\
4-Nitrophenyl butyrate & 20.769 & 0.040 & 1.926 \\
4-Nitrophenyl laurate & 49.690 & 0.017 & 0.349 \\
\hline
\end{tabular}

effect was observed on the values of $k_{\text {cat }} / K_{\mathrm{m}}$ and $k_{\text {cat }}$ parameters, at both cases of high $\left[\mathrm{CaCl}_{2}\right]$ and $\left[\mathrm{MgCl}_{2}\right]$, whereas a positive effect was observed on the $K_{\mathrm{m}}$ values $(\sim 150 \%)$ for both salts; unambiguously, increased $\left[\mathrm{CaCl}_{2}\right]$ and/or $\left[\mathrm{MgCl}_{2}\right]$ in the enzymatic reaction mixture contributed in decreasing both the catalytic efficiency, and the turnover of LipSm, affecting also the lipase-substrate affinity. The effect of both low and high $\left[\mathrm{MnCl}_{2}\right]$ in the reaction mixture was found almost similar; the observed decrease in the values of both $k_{\text {cat }} / K_{\mathrm{m}}$ and $k_{\text {cat }}$ was accompanied by no effect on the $K_{\mathrm{m}}$, more likely due to chelating effects which are easily formed by a multivalent transition element $(\mathrm{Mn})$ (the effect of metallic salts on the Michaelis-Menten parameters of LipSm is depicted in more detail in Additional file 2).

The profiles of parameters $k_{\text {cat }} / K_{\mathrm{m}}$ and $k_{\text {cat }}$ versus the $\mathrm{pH}$ value were obtained during the hydrolysis of substrates Ac-4-NPh and Bu-4-NPh by LipSm, and are depicted in Fig. 6a, b, respectively; in the case of substrate Ac-4-NPh (Fig. 6a) it is obvious that the enzyme species which correspond to the parameter $k_{\text {cat }} / K_{\mathrm{m}}$ (i.e. the ES complex-narrower profile) is much less stable as compared to that corresponding to $k_{\text {cat }}$ (i.e. the $\mathrm{E}_{\text {acyl }}-$ broader profile). Moreover, it should be emphasized that the $\mathrm{pH}$
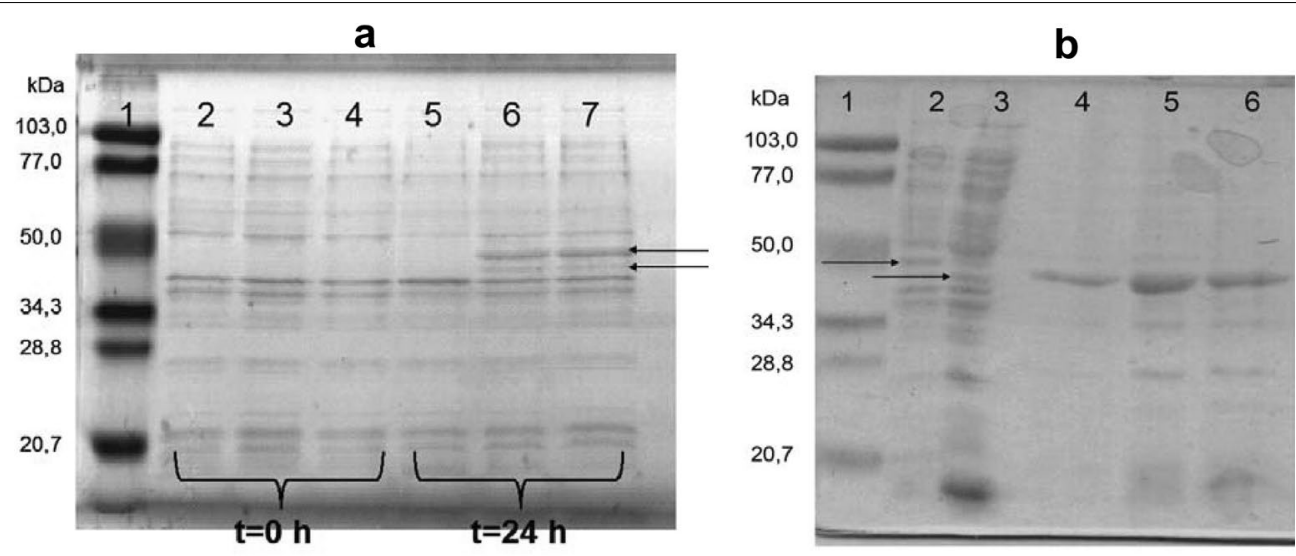

Fig. 5 SDS-PAGE. a The whole cell protein extracts of two clones during overexpression, where in lane 1: MM marker; lanes 2, 5: BL21(DE3)/pET29c; lanes 3, 6: BL21(DE3)/pET29c::lip clone a; lanes 4, 7: BL21(DE3)/pET29c:.lip clone b, b lipase purification steps, where in lane 1: MM marker; lane 2: crude protein extract at $24 \mathrm{~h}$ induction; lane 3: total soluble protein extract after cell lysis and centrifugation; lane 4: purified lipase LipSm fraction 1; lane 5: purified lipase LipSm fraction 2; lane 6: purified lipase LipSm fraction 3 

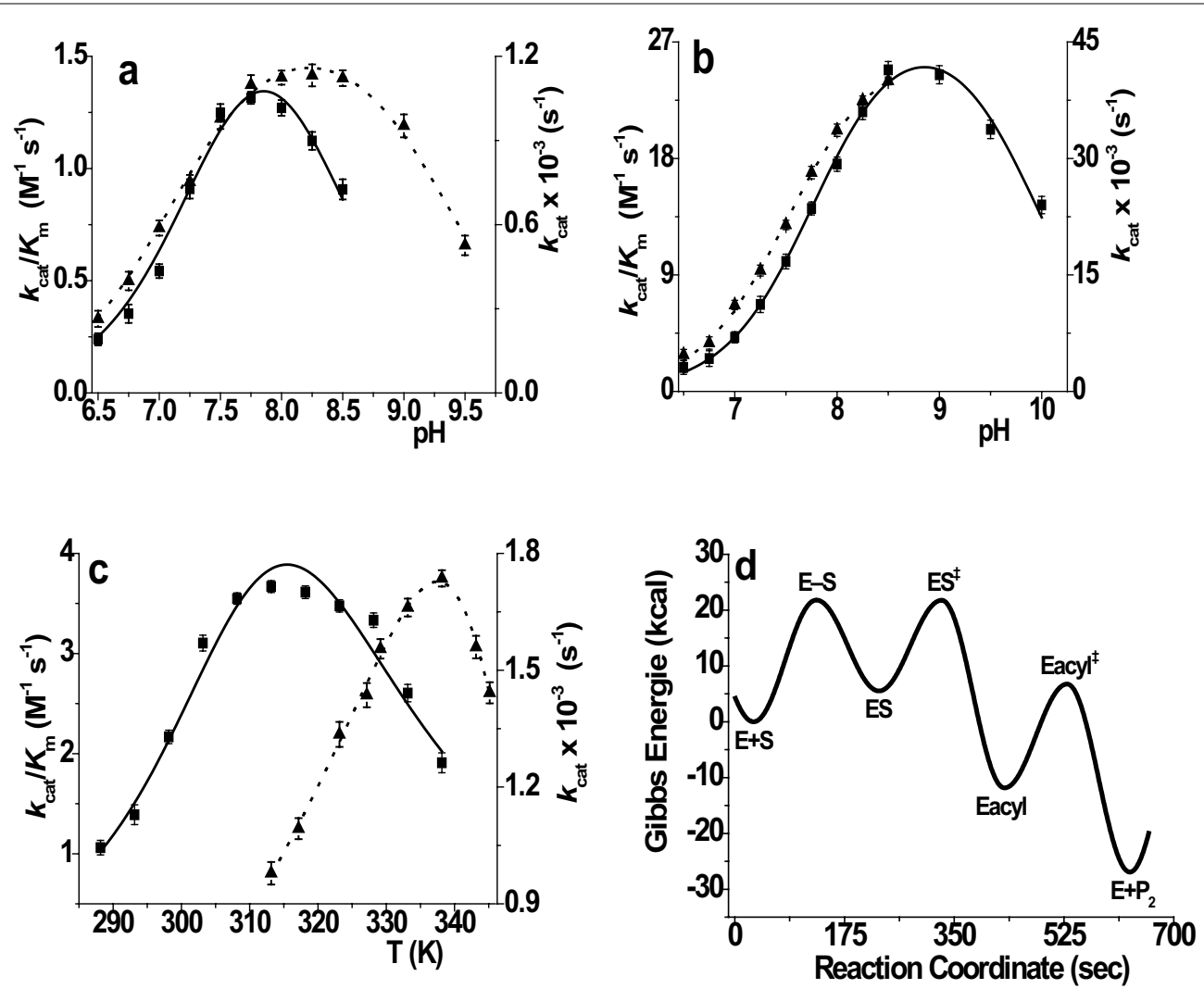

Fig. 6 Kinetic analysis of LipSm. Merged curves of the dependencies of Michaelis-Menten parameters $k_{\text {cat }} / K_{m}$ (filled square solid lines) and $k_{\text {cat }}$ (filled triangle dotted lines) versus the $\mathrm{pH}$ value, as well as versus the absolute temperature, and an energy diagram: a estimates of parameters $k_{\text {cat }} / K_{m}$ and $k_{\text {cat }}$ versus the $\mathrm{pH}$ value, using 4-nitrophenyl acetate as substrate, where $\left(k_{\text {cat }} / K_{m}\right)^{l i m}=2.33 \pm 0.26 \mathrm{M}^{-1} \mathrm{~s}^{-1}, \mathrm{p} K_{\mathrm{a} 1}=7.42 \pm 0.10$ and $\mathrm{p} K_{\mathrm{a} 2}=8.29 \pm 0.10$, as well as $\left(k_{\mathrm{cat}}\right)^{\lim }=1.33 \times 10^{-3} \pm 0.03 \times 10^{-3}, \mathrm{p} K_{\mathrm{a} 1}=7.09 \pm 0.03$ and $\mathrm{p} K_{\mathrm{a} 2}=9.36 \pm 0.04 ; \boldsymbol{b}$ estimates of parameters $k_{\text {cat }} / K_{\mathrm{m}}$ and $k_{\text {cat }}$ versus the $\mathrm{pH}$ value, using 4-nitrophenyl butyrate as substrate, where $\left(k_{\text {cat }} / K_{\mathrm{m}}\right)^{\text {lim }}=29.24 \pm 0.71 \mathrm{M}^{-1} \mathrm{~s}^{-1}, \mathrm{p} K_{\mathrm{a} 1}=7.78 \pm 0.04$ and $\mathrm{pK}_{\mathrm{a} 2}=9.93 \pm 0.05$, as well as $\left(k_{\mathrm{cat}}\right)^{\lim }=44.78 \times 10^{-3} \pm 0.87 \times 10^{-3}, \mathrm{p} K_{\mathrm{a} 1}=7.52 \pm 0.02$ and $\mathrm{p} K_{\mathrm{a} 2}=10.33 \pm 0.60 ; \mathbf{c}$ the dependencies of parameters $k_{\text {cat }} / K_{m}$ and $k_{\text {cat }}$ versus the absolute temperature, using 4-nitrophenyl acetate as substrate; $\mathbf{d}$ energy diagram of hydrolysis of substrate 4-nitrophenyl acetate by the novel lipase (the value of Arrhenius pre-exponential factor was assumed as $6 \times 10^{12} \mathrm{~s}^{-1}$ )

optimum value for the $k_{\text {cat }}$ parameter is shifted to more alkaline values at about $0.38 \mathrm{pH}$ units, versus that for the $k_{\text {cat }} / K_{\mathrm{m}}$ parameter. These results are also supported from the estimated values of two $\mathrm{p} K_{\mathrm{a}}$, in both cases of the $k_{\text {cat }} / K_{\mathrm{m}}$ and $k_{\text {cat }}$ parameters. In the case of $k_{\text {cat }} / K_{\mathrm{m}}$, a $\mathrm{p} K_{\mathrm{a}}$ value of 7.42 could be assigned to the formation of the ES complex (ionization of catalytic histidine), whereas a $\mathrm{p} K_{\mathrm{a}}$ value of 8.29 could be assigned to the formation of an activated ES complex (tetrahedral intermediate) more likely due to the nucleophilic attack of the $\mathrm{NH}$-group of the scissile amide bond onto the neutral imidazole of the catalytic histidine. Furthermore, in the case of $k_{\text {cat }}$, a $\mathrm{p} K_{\mathrm{a}}$ value of 7.09 could be assigned to the formation of the $\mathrm{E}_{\mathrm{acyl}}$ species, whereas a $\mathrm{p} K_{\mathrm{a}}$ value of 9.36 could be assigned to the transformation of $E_{a c y l}$ species to free enzyme and the product (acid). Furthermore, the profiles of parameters $k_{\text {cat }} / K_{\mathrm{m}}$ and $k_{\text {cat }}$ versus the $\mathrm{pH}$ value exhibit similar $\mathrm{pH}$ optima, in the case of the hydrolysis of substrate $\mathrm{Bu}-4-\mathrm{NPh}$, as it is depicted in Fig. 6b. These results imply that both enzyme species, i.e. the ES complex, as well as the $\mathrm{E}_{\mathrm{acy}}$, are equally stable, although there is a lack of experimental data in $\mathrm{pH}$ values $>8.5$ due to the limited solubility of the used substrate in the reaction buffer.

In the latter case, the estimated values of the two $\mathrm{p} K_{\mathrm{a}}$ (for both $k_{\text {cat }} / K_{\mathrm{m}}$ and $k_{\text {cat }}$ parameters) differ significantly from the corresponding $\mathrm{p} K_{\mathrm{a}}$ values, which were estimated for the substrate Ac-4-NPh, and a similar assignment could be valid for these $\mathrm{p} K_{\mathrm{a}}$ values, as in the case of substrate Ac-4-NPh, by taking into account also that the $\mathrm{pH}$ maxima in the hydrolysis of substrate $\mathrm{Bu}-4-\mathrm{NPh}$ were shifted to more alkaline values $(\sim 8.87)[22,23]$.

Moreover, the profiles of the parameters $k_{\text {cat }} / K_{\mathrm{m}}$ and $k_{\text {cat }}$ versus the absolute temperature at $\mathrm{pH} 8.00$ were obtained and are depicted in Fig. 6c; LipSm exhibited 
optimum $k_{\text {cat }} / K_{\mathrm{m}}$ and $k_{\text {cat }}$ values at about 42.3 and $64.5^{\circ} \mathrm{C}$, respectively, while it maintained full activity up to $70^{\circ} \mathrm{C}$ after $30 \mathrm{~min}$ of incubation, and then measuring its activity at $40{ }^{\circ} \mathrm{C}$. These profiles were used to estimate the rate constants $k_{1}, k_{-1}, k_{2}$ and $k_{3}$, the corresponding activation energies, as well as the energy diagram (Fig. 6d). Furthermore, in agreement with the aforementioned results are the following i.e. (a) the profiles of $k_{\text {cat }} / K_{\mathrm{m}}$ and $k_{\text {cat }}$ versus the $\mathrm{pH}$ value showed that the ES complex is apparently higher at about 5.5 and $16.3 \mathrm{kcal}$ from the species $\mathrm{E}+\mathrm{S}$ and $E_{\text {acyl }}$, respectively, and (b) the estimated values of $\Delta H^{\ddagger}, \Delta S^{\ddagger}$ and $\Delta G^{\ddagger}$ for the parameters $k_{\text {cat }} / K_{\mathrm{m}}$ and $k_{\text {cat }}$, by mentioning out the effect on the entropies of activation during the formation of species ES and $\mathrm{E}_{\text {acyl }}$, respectively $\left(\Delta S_{k_{\text {cat }} / K_{\mathrm{m}}}^{\ddagger}-\Delta S_{k_{\text {cat }}}^{\ddagger}=109.83 \mathrm{~kJ} \mathrm{~mol}^{-1} \mathrm{~K}^{-1}\right)$.

In addition, the shift of the absolute temperature profile of $k_{\text {cat }}$, towards higher temperatures, could verify that the reaction course from ES towards the products (substrate $\mathrm{AC}-4-\mathrm{NPh}$ ) dominates at higher temperatures; thus, the following relation are valid: $k_{\text {cat }} / K_{\mathrm{m}} \neq k_{1}$ and $k_{\text {cat }} / K_{\mathrm{m}}=k_{1} k_{2} /\left(k_{-1}+k_{2}\right)$ [24].

\section{Discussion}

A new environmental $S$. maltophilia strain designated Psi-1 which exhibits lipase activity was isolated from a sample originating from a waste treatment facility. One of the strain's lipase genes, designated lipSm and encoding a putative secreted lipase (LipSm) was successfully cloned and overexpressed in E. coli. LipSm, which was isolated, purified and analyzed biochemically and kinetically, is the second characterized lipase from S. maltophilia after the recently published $S$. maltophilia LipSM54 [15]. The two S. maltophilia lipase genes and their corresponding enzymes share low sequence identities, 62 and 23\%, respectively. Furthermore, they exhibit distinct structural and biochemical properties, thus belonging to different lipase families (Fig. 2).

LipSm clustered together with the putative bacterial lipases from various strains of $S$. maltophilia, $P$. geniculata and $P$. aeruginosa, while $S$. pavanii lipases are also found in the same phylogenetic clade, albeit at a slightly greater phylogenetic distance (Fig. 2). Furthermore, important structural/functional features of these enzymes exhibit strong identity/similarity among themselves. These features, presented in Fig. 4, are: (i) the pentapeptide segment surrounding the catalytic serine residue (GHSQG for $S$. maltophilia strains, $P$. geniculata and $P$. aeruginosa and GYSQG for $S$. pavanii strains) and (ii) the conserved composition and positioning of the amino acid residues constituting the oxyanion hole.

Unfortunately, all other lipases belonging to the same clade as LipSm are uncharacterized and therefore no further comparison is possible. As depicted in Fig. 2, next to LipSm clade finds itself another clade consisting of putative actinobacterial lipases (Gordonia sp. and Rhodococcus sp.). This group of enzymes though, exhibits moderate sequence identities with LipSm (up to $48 \%$ ). Furthermore, LipSm clade is clearly distal from any of the previously described lipase families (Fig. 2). These results suggest the classification of LipSm as the first characterized member of a novel bacterial lipase family, indexed XVIII.

Despite the low sequence similarity between the two enzymes, LipSm 3D homology model constructed using CALA (PDB ID 2VEO) as template, reveals a high semblance of the two structures, which includes the catalytic triad and the lid domain (Fig. 3a). However, it is noteworthy that LipSm lacks the additional active-site flap (2VEO: $\mathrm{E}^{426}$ up to $\mathrm{E}^{436}$ ), which is present in CALA [25]. The absence of the latter structure leads to a semi covered catalytic site for LipSm that allows the enzyme to act without interfacial activation, when small substrates are bound, as it was found in the docking studies. This was further experimentally substantiated by the fact that LipSm was active in reaction mixtures lacking surfactants (i.e. Triton X-100), when Ac-4-NPh or Bu-4-NPh were used as substrates (Fig. 6). Such microbial lipases that, despite having a lid, do not require interfacial activation with some substrates, are rare and include lipases from $P$. aeruginosa and Burkholderia (Pseudomonas) glumae, as well as, $C$. antarctica lipase B [26, 27]. It is noteworthy, that this novel enzyme has also an unusual Y-type oxyanion hole. Lipases, which contain the Y-type oxyanion hole, have been classified as Y-class lipases. To the Y-class have been assigned the $C$. antarctica lipase A [28] along with other fungal lipases of the superfamily (abH38). This structural feature of LipSm is unusual among bacterial lipases. The only other known bacterial lipases, which contain a Y-type oxyanion hole, as well as common structural features with CALA, are: (i) LipR and LipBX from Rhodococcus sp. and Burkholderia cenocepacia, respectively, both representatives of a distinct family proposed by Bassegoda et al. [29] and (ii) LipJ2 from Janibacter sp., the first characterized member of family XVII [17]. Despite these structural similarities, sequence identity of LipSm to the above mentioned characterized enzymes is low (20\% to LipR and LipBX, approximately $25 \%$ to LipJ2), constituting clearly distinguishable families as depicted in Fig. 2.

In addition, emphasis should be given on the alkaliphilic and thermotolerant features, exhibited by this novel lipase during biochemical and kinetic studies. Regarding the $\mathrm{pH}$ effect on the activity of LipSm, it was proven that this enzyme possesses a slightly alkaliphilic character along with an augmented stability in its productive status, exhibiting its $\mathrm{pH}$ optima within the 
range of approximately 8-9 (Fig. 6a, b). These results are in perfect agreement with the optimum $\mathrm{pH}$ values reported for most lipases which lie between 7 and 9 [30]. In reference to LipSm thermostability, the enzyme maintained full activity up to $70{ }^{\circ} \mathrm{C}$ after $30 \mathrm{~min}$ of incubation. This experimental finding is further supported by in silico sequence analysis of LipSm that revealed the occurrence of the AXXXA motif nine times in the mature protein sequence, a structural signature of thermostable lipases since this motif is reported to cause better structural stability by strong van der Waals interaction in thermostable proteins [31, 32]. Furthermore, alanine residues in LipSm constitute $16.71 \%$ of the total amino acid composition, while the corresponding average value of a total of twenty-three microbial thermostable lipases, including Pseudomonas sp. lipases and CALA, is $8.88 \%$ [21]. The higher percentage of Ala is reported to attribute positively to lipase's thermal stability [21].

\section{Conclusions}

Lipases are enzymes which are used in a variety of biotechnological applications being able to catalyze a broad spectrum of reactions. This fact has led to an increased interest in the isolation of novel microbial lipases with particular properties, in order to be exploited as biocatalysts in various industrial applications. To this end, a novel lipase gene (lipSm) from S. maltophilia strain Psi-1 was cloned and overexpressed and the deduced enzyme LipSm was purified and characterized. The phylogenetic analysis of the novel enzyme suggests the establishment of a new bacterial lipase family (XVIII) with LipSm being its first characterized member. Furthermore, 3D modeling revealed that LipSm possesses a certain lid structure which enables it to act without the need for interfacial activation when small substrates are bound. This feature along with LipSm alkaliphilic and thermostable character, make LipSm a potential advantageous biocatalyst in industry and biotechnology.

\section{Methods}

\section{Screening and isolation of lipase producing organisms}

Sludge samples were collected from the waste treatment facilities in Volos and at Psittaleia (Greece) [33] and each cultivated in Luria-Bertani (LB) medium at $30{ }^{\circ} \mathrm{C}$, for $24 \mathrm{~h}$. Samples of the batch cultures were serially diluted on LA plates and incubated at $30^{\circ} \mathrm{C}$, for $24-48 \mathrm{~h}$. Individual colonies with a distinct phenotype were removed and purified by repeated plate streaking, to obtain pure colonies and cultures. Representatives of each phenotype were further streaked on Rhodamine B-olive oil agar plates according to Kouker and Jaeger [19], in order to detect those, exhibiting lipase activity.

\section{Molecular techniques}

Commercial kits Nucleospin Tissue, Nucleospin Plasmid and NucleoSpin Extract 2 in 1 were used to isolate genomic DNA, plasmid DNA and to extract DNA bands from agarose gels respectively, according to the suppliers' recommendations (Macherey-Nagel, Düren, Germany). All Polymerase Chain Reactions (PCR) reactions were performed using the Kapa Hifi PCR System (KAPABIOSYSTEMS, Massachusetts, USA) according to the manufacturers' recommendations, except for the variation of annealing temperatures whenever needed. All PCR primers were purchased from VBC-Biotech (Vienna, Austria). Vector pBlueScript II KS (+) (Stratagene, CA, USA) was used for all cloning experiments, while Escherichia coli (E. coli) strain DH5 $\alpha$ served as the recombinant plasmid host [34].

Genomic DNA from S. maltophilia Psi-1 served as the template for PCR to amplify the 16S rDNA gene, using the primer pair 16SF (5'-AGTTTGATCCTGG CTCAG- $3^{\prime}$ ) and 16SR (5'-AGAAAGGAGGTGATCC AGCC-3') [35] and an annealing temperature of $60{ }^{\circ} \mathrm{C}$. For the isolation of a large DNA fragment $(1850 \mathrm{bp})$ containing a putative secreted lipase gene, primers SMLF (5'-AGTGGCCGAAGTACCCGTGG-3') and SMLR (5'-CTGCCGGCCTATGACGTGCT-3') were employed with an annealing temperature of $68{ }^{\circ} \mathrm{C}$. The produced amplicon was cloned and the recombinant plasmid DNA served as a template to amplify the contained putative lipSm ORF. To this end, primer pair SMLPETF (5'-GAGCGCCATATGACCCCACCGCC-3') and SMLPETR (5'-ATTCCTCGAGCGGGGACTCGTCCAGT ACCTG-3') containing restriction sites for NdeI and XhoI, respectively, was used to amplify lipSm ORF, at an annealing temperature of $70{ }^{\circ} \mathrm{C}$. Cloned inserts were sequenced by CEMIA (Larissa, Greece). Taxonomic analysis was conducted using the GenBank BLAST program [36]. Phylogenetic and molecular evolutionary analysis was performed using MEGA software [37].

Finally, lipSm ORF was cloned in the pET29c(+) expression vector (Novagen, Wisconsin, USA) following restriction of both the expression vector and the gelpurified insert of clone pBlueScript II KS (+)/lipSm with NdeI-XhoI (Takara Bio Inc., Shiga, Japan). The resulting pET29c::lipSm construct was transformed into E. coli BL21(DE3) according to the method of Chung and Miller [38] for expression analysis.

\section{Amino acid sequence alignment, phylogeny, and structural analysis of LipSm}

The web tool ORF Finder (http://www.ncbi.nlm.nih. gov/projects/gorf/) was used to identify the lipSm open reading frame (ORF). In silico translation to deduce the putative amino acid sequence (LipSm) corresponding 
to lipSm ORF was achieved by ExPASy translate tool [39]. Pfam web-tool [40] was used to assign LipSm to an enzyme class. SignaIP (version 4.1) software [41] was used to detect the occurrence of putative signal peptides. BLAST searches were performed to find the closest evolutionary relationships of LipSm [36]. ClustalOmega [42] was used to align LipSm with related sequences, whereas the phylogenetic position of LipSm was determined using the software MEGA [37]. A threedimensional model for the target protein was generated using the SWISS-MODEL protein structure homologymodeling server [43]. Finally, computational analysis was applied in this work, on a Linux Platform, using the Schrödinger Software suite, ver. 2014-4 (Schrödinger LLC, Mannheim, Germany). The output generated by the SWISS-MODEL was further prepared by the Protein Preparation Wizard module. The molecular structure of the butyl-butyrate was built and prepared using the Build and the LigPrep module, respectively. Different conformations were generated with the Advanced Search of ConfGen module, by selecting water as solvent and the truncated Newton (TCNG) method for minimization (100 iterations). A $30 \times 30 \times 30 \AA^{3}$ grid box with $10 \times 10 \times 10 \AA^{3}$ default inner box was centered onto the catalytic triad $\left(\mathrm{S}^{154}, \mathrm{D}^{299}, \mathrm{H}^{330}\right)$. All the output conformers were docked using the extra-precision (XP) mode of Glide docking module, and the top pose of the complex of LipSm with butyl-butyrate was used for the specification of oxyanion hole.

\section{Overexpression and purification of lipSm gene}

Cells containing the pET29c::lipSm plasmid were incubated in 2 L LB containing kanamycin sulfate $(\mathrm{Kn})$ $\left(50 \mu \mathrm{g} \mathrm{mL} \mathrm{m}^{-1}\right)$. The culture was incubated at $37^{\circ} \mathrm{C}$ with aeration, in a $10 \mathrm{~L}$ Bioflo 110 bioreactor, equipped with a cooling/heating system (New Brunswick Scientific, Enfield, CT, USA). Culture was induced at an $A_{600}$ of 0.6 by adding $0.5 \mathrm{mM}$ isopropyl- $\beta$-D-1-thiogalactopyranoside (IPTG), and incubation was continued at $16{ }^{\circ} \mathrm{C}$ overnight. The cells were harvested by centrifugation, washed with $100 \mathrm{mM}$ Tris- $\mathrm{HCl}, \mathrm{pH} 8.0$, and stored at $-20{ }^{\circ} \mathrm{C}$ [crude (whole cell) protein extract, lane 2 in Fig. 5b]. The cell pellet of the $2 \mathrm{~L}$ culture was thawed and resuspended in $20 \mathrm{mM}$ sodium phosphate buffer, $\mathrm{pH}$ 7.6, containing $250 \mathrm{mM}$ sodium chloride $(\mathrm{NaCl})$ and $2 \% \mathrm{w} / \mathrm{v}$ TWEEN 20 , at a ratio of approximately $5 \mathrm{~mL}$ buffer $\mathrm{g}^{-1}$ of dry cells. The suspension was subjected to ultrasonic treatment (10 pulses $10 \mathrm{~s}^{-1} 300 \mathrm{~W}^{-1}$ with interval pauses of $10 \mathrm{~s}$ for cooling the samples on ice) and centrifuged. The soluble supernatant fraction (total soluble protein extract, lane 3 in Fig. 5b) was loaded on a $5 \mathrm{~mL}$ HisTrap ff crude column using the ÄKTA FPLC protein purification system (GE Healthcare Bio-Sciences AB, Danderyd, Sweden), which was previously equilibrated with 5 column volumes (CVs) of an appropriate buffer $(20 \mathrm{mM}$ sodium phosphate buffer, $\mathrm{pH}$ 7.6, containing $250 \mathrm{mM} \mathrm{NaCl}$, $1 \% \mathrm{w} / \mathrm{v}$ TWEEN 20 and $20 \mathrm{mM}$ imidazole). In order to remove the unbound material, the column was washed with $10 \mathrm{CVs}$ of the same buffer. Subsequently, LipSm was eluted in three successive steps using: (a) a $5 \mathrm{CVs}$ length imidazole gradient $(20-100 \mathrm{mM})$ of the aforementioned buffer, (b) $7 \mathrm{CVs}$ length of the same buffer isocratic in imidazole (140 mM), and (c) $5 \mathrm{CVs}$ length of the same buffer isocratic in imidazole but at higher concentration (500 mM) (Purified lipase LipSm Fractions, lanes 4-6 in Fig. 5b). Protein concentration was estimated by the method of Bradford [44] and protein profile was analyzed by Sodium Dodecyl Sulphate Polyacrylamide Gel Electrophoresis (SDS-PAGE) [45].

\section{Solutions, activity and kinetic measurements}

All activity and kinetic measurements throughout this study were carried out in aqueous buffers of $100 \mathrm{mM}$ Tris- $\mathrm{HCl}, \mathrm{pH} 8.0$ containing $1 \%$ Triton $\mathrm{X}-100 \mathrm{w} / \mathrm{v}$ at $40{ }^{\circ} \mathrm{C}$, except, if otherwise stated. In all cases, the aqueous reaction media contained $5 \% \mathrm{v} / \mathrm{v}$ dimethylsulfoxide (DMSO), to increase the solubility of the used substrates $[6,23,24,46]$.

The kinetic measurements were performed spectrophotometrically by initial velocities at $405 \mathrm{~nm}$, and at the appropriate $\mathrm{pH}$ and temperature values of the reaction mixtures, where the active concentration of LipSm was $850 \mathrm{nM}$ for the substrates Ac-4-NPh and Bu-4-NPh, and $2200 \mathrm{nM}$ for the substrate La-4-Nph. Each reaction run was initiated by adding $10 \mathrm{~mL}$ of the appropriate substrate solution in DMSO and the release of the leaving group (4-nitrophenol) was recorded; all kinetic measurements were repeated eight times.

\section{Effect of metallic salts, and dependencies of $\mathrm{k}_{\mathrm{cat}} / \mathrm{K}_{\mathrm{m}}, \mathrm{k}_{\mathrm{cat}}$ and $\mathrm{K}_{\mathrm{m}}$ of LipSm vs. $\mathrm{pH}$ and temperature}

Kinetic measurements were performed at both low [S] $\left(<20 \times K_{\mathrm{m}}\right)$ and at high [S] $\left(>5 \times K_{\mathrm{m}}\right)$ of the substrate Ac-4-NPh in order to investigate the effect of metallic salts $\mathrm{CaCl}_{2}, \mathrm{MgCl}_{2}, \mathrm{MnCl}_{2}$, and $\mathrm{NaCl}$ on the MichaelisMenten parameters of the novel lipase at various starting salt concentrations ( 1 and/or $10.0 \mathrm{mM}$ ), and estimates of the Michaelis-Menten parameters $k_{\text {cat }} / K_{\mathrm{m}}, k_{\text {cat }}$, and $K_{\mathrm{m}}$, were obtained. Additional measurements were performed using both substrates Ac-4-NPh and $\mathrm{Bu}-4-\mathrm{NPh}$ at different $\mathrm{pH}$ values and at $40{ }^{\circ} \mathrm{C}$, and then at varying temperatures and at $\mathrm{pH} 8.00$, without $1 \%$ Triton X-100 $\mathrm{w} / \mathrm{v}$, as previously described [23]. The thermo tolerance of LipSm was tested by incubating the corresponding enzyme preparations at a range of temperatures $\left(20{ }^{\circ} \mathrm{C}\right.$ up to $70{ }^{\circ} \mathrm{C}$ ), for $30 \mathrm{~min}$, and then by performing activity 
measurements using these preparations at the temperature of $40^{\circ} \mathrm{C}$.

\section{Analysis of data}

The experimental data of the dependencies of Michaelis-Menten parameters $k_{\text {cat }} / K_{\mathrm{m}}, k_{\text {cat }}$ and $K_{\mathrm{m}}$ versus the substrate concentration, $\mathrm{pH}$ values and absolute temperature, were analyzed by means of the familiar Michaelis-Menten equation, as well as by Eqs. (1)-(4) [46, 47]. In these equations, $k_{\text {obs }}$ and $(k)^{\lim }$ are referred to either parameter $k_{\text {cat }} / K_{\mathrm{m}}$ or $k_{\text {cat }}$.

$$
\begin{aligned}
& k_{\mathrm{obs}}=\frac{(k)^{\lim }}{1+10^{\mathrm{p}} K_{\mathrm{a} 1}-\mathrm{pH}+10^{\mathrm{pH}-\mathrm{p} K_{\mathrm{a} 2}}} \\
& \text { for } k_{\text {cat }} / K_{\mathrm{m}}: \frac{k_{\mathrm{cat}}}{K_{\mathrm{m}}}=\left\{\frac{\alpha_{0} \mathrm{e}^{\left[\frac{\mathrm{E}_{\alpha}}{\mathrm{R}}\left(\frac{1}{\mathrm{~T}}-\frac{1}{\mathrm{~T}_{0}}\right)\right]}}{1+\alpha_{0} \mathrm{e}^{\left[\frac{\mathrm{E} \alpha}{\mathrm{R}}\left(\frac{1}{\mathrm{~T}}-\frac{1}{\mathrm{~T}_{0}}\right)\right]}}\right\}\left(k_{1}\right)_{0} \mathrm{e}^{\left[-\frac{\mathrm{E}_{1}}{\mathrm{R}}\left(\frac{1}{\mathrm{~T}}-\frac{1}{\mathrm{~T}_{0}}\right)\right]} \\
& \text { and } \frac{k_{\text {cat }}}{K_{\mathrm{m}}}=\frac{\left(k_{1}\right)_{0}\left(k_{2}\right)_{0} \mathrm{e}^{\left[\frac{-\left(\mathrm{E}_{1}+\mathrm{E}_{1}\right)}{\mathrm{R}}\left(\frac{1}{\mathrm{~T}}-\frac{1}{\mathrm{~T}_{0}}\right)\right]}}{\left(k_{-1}\right)_{0} \mathrm{e}^{\left[-\frac{\mathrm{E}_{-1}}{\mathrm{R}}\left(\frac{1}{\mathrm{~T}}-\frac{1}{\mathrm{~T}_{0}}\right)\right]}+\left(k_{2}\right)_{0} \mathrm{e}^{\left[-\frac{\mathrm{E}_{2}}{\mathrm{R}}\left(\frac{1}{\mathrm{~T}}-\frac{1}{\mathrm{~T}_{0}}\right)\right]}} \\
& \text { for } k_{\text {cat }}: k_{\text {cat }}=\frac{\left(k_{2}\right)_{0}\left(k_{3}\right)_{0} \mathrm{e}^{\left[\frac{-\left(\mathrm{E}_{2}+\mathrm{E}_{3}\right)}{\mathrm{R}}\left(\frac{1}{\mathrm{~T}}-\frac{1}{\mathrm{~T}_{0}}\right)\right]}}{\left(k_{2}\right)_{0} \mathrm{e}^{\left[-\frac{\mathrm{E}_{2}}{\mathrm{R}}\left(\frac{1}{\mathrm{~T}}-\frac{1}{\mathrm{~T}_{0}}\right)\right]}+\left(k_{3}\right)_{0} \mathrm{e}^{\left[-\frac{\mathrm{E}_{3}}{\mathrm{R}}\left(\frac{1}{\mathrm{~T}}-\frac{1}{\mathrm{~T}_{0}}\right)\right]}}
\end{aligned}
$$

Eyring equation: $\mathrm{T} \times[\ln (k / \mathrm{T})]$

$$
=\mathrm{T} \times\left[\ln \left(k_{B} / \hbar\right)+\Delta S^{\ddagger} / R\right]-\Delta H^{\ddagger} / R
$$

the kinetic data and revised the manuscript. A-SA provided critical feedback on the designing of molecular experiments and revised the manuscript. EH supervised the whole project and contributed to get the manuscript to its final version. All authors read and approved the final manuscript.

\section{Author details}

${ }^{1}$ Enzyme Biotechnology and Genetic Engineering Group, University of loannina, 45110 loannina, Greece. ${ }^{2}$ Department of Biological Applications \& Technologies, University of loannina, University Campus, 45110 loannina, Greece.

\section{Acknowledgements}

Not applicable.

\section{Competing interests}

The authors declare that they have no competing interests.

\section{Availability of data and materials}

All data generated or analyzed during this study are included in this published article (and its additional information files).

\section{Consent for publication}

Not applicable.

\section{Ethics approval and consent to participate}

Not applicable.

\section{Funding}

This article is in line of a research project co-financed by the European Union (European Regional Development Fund-ERDF), through the operational programs for "competitiveness and entrepreneurship" and regions in transition "Cooperation 2011_Partnerships of Production and Research Institutions in Focused Research and Technology Sectors", of the National Strategic Reference Framework (NSRF) 2007-2013, and the Hellenic Ministry of Education, Lifelong Learning and Religious Affairs—General Secretariat for Research and Technology (Contract Nr. 11SYN-8-839).

\section{Publisher's Note}

Springer Nature remains neutral with regard to jurisdictional claims in published maps and institutional affiliations.

Received: 14 October 2017 Accepted: 27 January 2018

Published online: 08 February 2018

\section{Additional files}

Additional file 1. Complete sequence alignments among mature forms of LipSm and members of its clade. Protein sequences exhibit identities with each other ranging between 85 and 98\% (as calculated by Clustal2.1).

Additional file 2. Effect of metallic salts on the Michaelis-Menten parameters of LipSm.

\section{Abbreviations}

CALA: Candida antarctica lipase A; Ac-4-NPh: 4-nitrophenyl acetate; Bu-4-NPh: 4-nitrophenyl butyrate; La-4-NPh: 4-nitrophenyl laurate; OFR: open reading frame.

\section{Authors' contributions}

MP and MK isolated strain Psi-1. MP and PM characterized the strain. MP designed and performed cloning and expression experiments, analyzed data, conducted bioinformatic sequence analyses and took the lead in writing the manuscript. AF, P-YS and OAG purified the protein, conducted the computational modeling and wrote the respective parts of the manuscript. P-YS, OAG and EMP performed the biochemical and kinetic characterization of the protein. P-YS and EMP contributed to the interpretation of these results and wrote this part of the paper. EMP supervised the work of AF, P-YS and OAG, analyzed

\section{References}

1. Stergiou PY, Foukis A, Filippou M, Koukouritaki M, Parapouli M, Theodorou $\mathrm{LG}$, et al. Advances in lipase-catalyzed esterification reactions. Biotechnol Adv. 2013;31:1846-59.

2. Gupta R, Gupta N, Rathi P. Bacterial lipases: an overview of production, purification and biochemical properties. Appl Microbiol Biotechnol. 2004;64:763-81.

3. Bajaj A, Lohan P, Jha PN, Mehrotra R. Biodiesel production through lipase catalyzed transesterification: an overview. J Mol Catal B Enzym. 2010;62:9-14.

4. Kamal MZ, Yedavalli P, Deshmukh MV, Rao NM. Lipase in aqueouspolar organic solvents: activity, structure, and stability. Protein Sci. 2013;22:904-15.

5. Sharma D, Sharma B, Shukla AK. Biotechnological approach of microbial lipases: a review. Biotechnology. 2011;10:23-40.

6. Kokkinou M, Theodorou LG, Papamichael EM. Aspects on the catalysis of lipase from porcine pancreas (type VI-s) in aqueous media: development of ion-pairs. Braz Arch Biol Technol. 2012;55:231-6.

7. Sharma R, Chisti Y, Banerjee UC. Production, purification, characterization, and applications of lipases. Biotechnol Adv. 2001;19:627-62.

8. Andualema B, Gessesse A. Microbial lipases and their industrial applications: review. Biotechnology. 2012;11:100-18.

9. Ollis DL, Cheah E, Cygler M, Dijkstra B, Frolow F, Franken SM, et al. The alpha/beta hydrolase fold. Protein Eng. 1992;5:197-211. 
10. Lotti M, Alberghina L. Lipases: molecular structure and function. In: Polaina J, MacCabe AP, editors. Industrial enzymes structure, function and applications. Dordrecht: Springer; 2007. p. 263-82.

11. Rehm S, Trodler P, Pleiss J. Solvent-induced lid opening in lipases: a molecular dynamics study. Protein Sci. 2010;19:2122-30.

12. Fischer M, Pleiss J. The Lipase Engineering Database: a navigation and analysis tool for protein families. Nucleic Acids Res. 2003;31:319-21.

13. Pleiss J, Fischer M, Peiker M, Thiele C, Schmid RD. Lipase Engineering Database: understanding and exploiting sequence-structure-function relationships. J Mol Catal B Enzym. 2000;10:491-508.

14. Arpigny JL, Jaeger KE. Bacterial lipolytic enzymes: classification and properties. Biochem J. 1999;343:177-83.

15. Li M, Yang LR, Xu G, Wu JP. Cloning and characterization of a novel lipase from Stenotrophomonas maltophilia GS11: the first member of a new bacterial lipase family XVI. J Biotechnol. 2016;228:30-6.

16. Zarafeta D, Moschidi D, Ladoukakis E, Gavrilov S, Chrysina ED, Chatziioannou A, et al. Metagenomic mining for thermostable esterolytic enzymes uncovers a new family of bacterial esterases. Sci Rep. 2016. https://doi. org/10.1038/srep38886.

17. Castilla A, Panizza P, Rodríguez D, Bonino L, Díaz P, Irazoqui G, et al. A novel thermophilic and halophilic esterase from Janibacter sp. R02, the first member of a new lipase family (Family XVII). Enzyme Microb Technol. 2017;98:86-95.

18. Wu JP, Li M, Zhou Y, Yang LR, Xu G. Introducing a salt bridge into the lipase of Stenotrophomonas maltophilia results in a very large increase in thermal stability. Biotechnol Lett. 2015;37:403-7.

19. Kouker G, Jaeger K-E. Specific and sensitive plate assay for bacterial lipases. Appl Environ Microbiol. 1987;53:211-3.

20. Crossman LC, Gould VC, Dow JM, Vernikos GS, Okazaki A, Sebaihia M, et al. The complete genome, comparative and functional analysis of Stenotrophomonas maltophilia reveals an organism heavily shielded by drug resistance determinants. Genome Biol. 2008;9:74-86.

21. Chakravorty D, Parameswaran S, Dubey VK, Patra S. In silico characterization of thermostable lipases. Extremophiles. 2011;15:89-103.

22. Papamichael EM, Bieth JG, Theodorou LG, Lymperopoulos K, Valasaki K. The elucidation of the mechanism of action of cysteine proteinases of the Papain-C1 family: possible biotechnological applications. In: Pandey A, Larroche C, Soccol C-R, Dussa C-G, editors. New horizons in biotechnology. New Delhi: Asiatech Publishers; 2009. p. 104-22.

23. Foukis A, Stergiou PY, Theodorou LG, Papagianni M, Papamichael EM. Purification, kinetic characterization and properties of a novel thermo-tolerant extracellular protease from Kluyveromyces marxianus IFO 0288 with potential biotechnological interest. Bioresour Technol. 2012;123:214-20.

24. Papamichael EM, Theodorou LG. Experimental and theoretical approaches in investigating enzymatic mechanisms: applications on the thermo-stable extracellular protease-A-17N-1 from Bacillus sp., with possible biotechnological interest. In: Pandey A, Larroche C, Soccol CR, Dussap CG, editors. Current topics on bioprocesses in food industry, vol. 3. New Delhi: Asiatech Publishers; 2010. p. 130-9.

25. Ericsson DJ, Kasrayan A, Johansson P, Bergfors T, Sandström AG, Bäckvall JE, et al. X-ray structure of Candida antarctica lipase A shows a novel lid structure and a likely mode of interfacial activation. J Mol Biol. 2008:376:109-19.

26. Alvaro G, Illanes A. Study cases of enzymatic processes. Chimioselective esterification of wood sterols. In: Illanes A, editor. Enzymes biocatalysis: principles and applications. New York: Springer; 2008. p. 292-322.

27. Haitz F, Rupp S, Hirth T, Zibek S. Lipase-catalyzed epoxidation of fatty compounds and alkenes. In: Grunwald P, editor. Industrial biocatalysis. Singapore: Pan Stanford Publishing; 2015. p. 723-82.

28. Widmann M, Juhl PB, Pleiss J. Structural classification by the Lipase Engineering Database: a case study of Candida antarctica lipase A. BMC Genom. 2010;11:123.

29. Bassegoda A, Pastor Fl, Diaz P. Rhodococcus sp. strain CR-53 LipR, the first member of a mew bacterial lipase family (Family X) displaying an unusual
Y-type oxyanion hole, similar to the Candida antarctica lipase clan. Appl Environ Microbiol. 2012;78:1724-32.

30. Willis WM, Marangoni AG. Enzymatic interesterification. In: Akoh CC, Min DB, editors. Food lipids: chemistry, nutrition, and biotechnology. 2 nd ed. New York: Marcel Dekker; 2002. p. 857-94.

31. Kleiger G, Grothe R, Mallick P, Eisenberg D. GXXXG and AXXXA: common a-helical interaction motifs in proteins, particularly in extremophiles. Biochemistry. 2002;41:5990-7.

32. Leonov H, Arkin IT. A periodicity analysis of transmembrane helices. Bioinformatics. 2005;21:2604-10.

33. Panagiotakis I, Mamais D, Pantazidou M, Marneri M, Parapouli M, Hatzil-

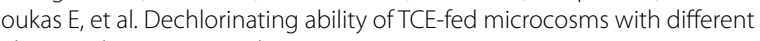
electron donors. J Hazard Mater. 2007;149:582-9.

34. Sambrook FJ, Russell DW. Molecular cloning: a laboratory manual. 4th ed. Cold Spring Harbor: Cold Spring Harbor Laboratory Press; 2001.

35. Karabika E, Kallimanis A, Dados A, Pilidis G, Drainas C, Koukkou Al. Taxonomic identification and use of free and entrapped cells of a new Mycobacterium sp., strain Spyr1 for degradation of polycyclic aromatic hydrocarbons (PAHs). Appl Biochem Biotechnol. 2009;159:155-67.

36. Altschul SF, Madden TL, Schäffer AA, Zhang J, Zhang Z, Miller W, et al. Gapped BLAST and PSI-BLAST: a new generation of protein database search programs. Nucleic Acids Res. 1997;25:3389-402.

37. Tamura K, Dudley J, Nei M, Kumar S. MEGA4: molecular evolutionary genetics analysis (MEGA) software version 4.0. Mol Biol Evol. 2007;24:1596-9.

38. Chung $\mathrm{CT}$, Miller $\mathrm{RH}$. A rapid and convenient method for the preparation and storage of competent bacterial cells. Nucleic Acids Res. 1988;16:3580.

39. Gasteiger E, Gattiker A, Hoogland C, Ivanyi I, Appel RD, Bairoch A. ExPASy: the proteomics server for in-depth protein knowledge and analysis. Nucleic Acids Res. 2003;31:3784-8.

40. Finn RD, Coggill P, Eberhardt RY, Eddy SR, Mistry J, Mitchell AL, et al. The Pfam protein families database: towards a more sustainable future. Nucleic Acids Res. 2016:44:D279-85.

41. Petersen TN, Brunak S, von Heijne G, Nielsen H. SignalP 4.0: discriminating signal peptides from transmembrane regions. Nat Methods. 2011;8:785-6.

42. McWilliam H, Li W, Uludag M, Squizzato S, Park YM, Buso N, et al. Analysis tool web services from the EMBL-EBI. Nucleic Acids Res. 2013;41:W597-600

43. Biasini M, Bienert S, Waterhouse A, Arnold K, Studer G, Schmidt T, et al. SWISS-MODEL: modelling protein tertiary and quaternary structure using evolutionary information. Nucleic Acids Res. 2014;42:W252-8.

44. Bradford MM. A rapid and sensitive method for the quantitation of microgram quantities of protein utilizing the principle of protein-dye binding. Anal Biochem. 1976;72:248-54.

45. Laemmli UK. Cleavage of structural proteins during the assembly of the head of bacteriophage T4. Nature. 1970;227:680-5.

46. Stergiou PY, Foukis A, Gkini OA, Bieth JG, Papamichael EM. Kinetic and computational analysis of the reversible inhibition of porcine pancreatic elastase: a structural and mechanistic approach. J Enzyme Inhib Med Chem. 2016;31:131-9.

47. Papamichael EM, Stergiou P-Y, Foukis A, Kokkinou M, Theodorou LG. Effective kinetic methods and tools in investigating the mechanism of action of specific hydrolases. In: Ekinci D, editor. Medicinal chemistry and drug design. Rijeka: INTECH Open Science; 2012. p. 235-74.

48. Levisson M, van der Oost J, Kengen SWM. Characterization and structural modeling of a new type of thermostable esterase from Thermotoga maritima. FEBS J. 2007;274:2832-42.

49. Charbonneau DM, Beauregard M. Role of key salt bridges in thermostability of $G$. thermodenitrificans EstGtA2: distinctive patterns within the new bacterial lipolytic enzyme family XIII.2. PLoS ONE. 2013;8:e76675. https:// doi.org/10.1371/journal.pone.0076675. 